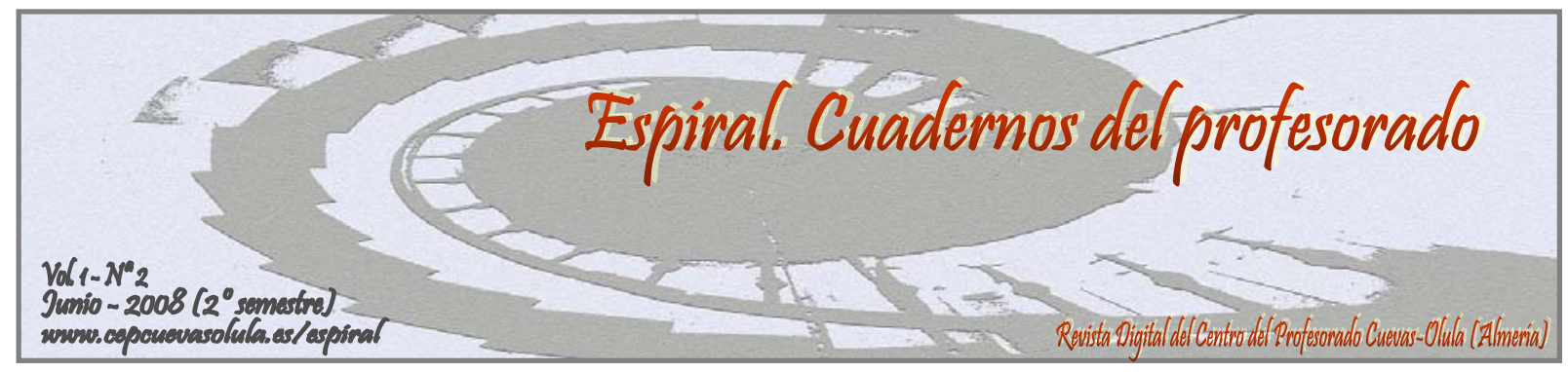

\title{
LA ZAMBRA EN AL-ANDALUS Y SU PROYECCIÓN HISTÓRICA
}

\author{
Emilia Martos Sánchez
}

\author{
I.E.S. Entresierras de Purchena (Almería)
}

Enviar correspondencia a: martosemi@gmail.com

RESUMEN: Este artículo pretende realizar una revisión de los orígenes y evolución de una de las pocas formas de danza andalusí de las que se conservan noticias: la zambra. El término zambra posee significados diversos que van desde lo que supone la danza en sí, a la acepción de fiesta. Esta forma de expresión corporal estuvo muy arraigada en la cultura de Al-Andalus, y pervivió durante la etapa morisca. Sin embargo, a finales del siglo XVI las tradiciones y el pueblo morisco eran cada vez peor vistos por los reyes cristianos, siendo definitiva su expulsión a principios del s. XVII. Paralelamente, a partir del siglo XV, asistimos a la llegada de la comunidad gitana a España, con quienes los musulmanes mantuvieron contacto, debido a su carácter también marginal. Esto conduce a pensar en un posible nexo entre la zambra morisca y la zambra gitana, cuestión en la que se profundizará a lo largo de este trabajo.

Palabras clave: zambra, danza, Al-Andalus, gitanos.

ABSTRACT: This article aims to review the origins and evolution of one of the few forms of dance of the Andalusian that are preserved news: zambra. The term zambra has various meanings ranging from implying the dance itself, the sense of festivity. This form of physical expression was deeply rooted in the culture of Al-Andalus, and survived during the Moorish. However, at the end of the sixteenth century Moorish traditions and people were becoming worse watched by Christian kings, with their final expulsion in early s. XVII. In parallel, from the fifteenth century, we witnessed the arrival of the gypsy community in Spain, with whom the Muslims had contact, because they are also marginal. This leads to thinking about a possible link between the Moorish zambra and Gypsy zambra issue that will deepen throughout this work.

Key words: zambra, dance, Al-Andalus, gypsies.

\section{1.- INTRODUCCIÓN.}

El presente artículo tiene como objetivo, el estudio de una de las pocas manifestaciones dancísticas andalusíes de las que se tiene constancia documental: la zambra. Ésta, no constituyó una mera manifestación musical, ya que sus implicaciones socio-políticas trasgredieron el territorio de lo artístico y fueron objeto de mira, así como de tajantes prohibiciones en los años posteriores a la Reconquista cristiana, sobre todo en el período transcurrido entre los años 1566-1570, tal como apunta Fernández Manzano (1985, p. 52-59)

No obstante, el término zambra nos conduce, sin premeditarlo, a la comunidad gitana, así como a sus fiestas y bailes tan popularmente conocidos. Es aquí cuando comienzan a surgir las dudas y los interrogantes; y nos preguntamos: ¿puede existir una relación entre aquella zambra andalusí y la zambra gitana?

Ésta es una de las principales cuestiones que intentaremos esclarecer en este estudio, el cual se 
ha divido en tres secciones principales, precedidas por una necesaria contextualización histórica. La primera sección ofrece una visión de lo que significó la zambra en Al-Andalus y en el período de expulsión de los moriscos, quedando constancia de ello en algunas noticias. $\mathrm{La}$ segunda se centra en la zambra gitana, donde se intentan analizar las posibles relaciones existentes entre la comunidad gitana y la morisca. Por último, dedicaremos un apartado a resumir una serie de conclusiones acerca de lo expuesto.

\section{2.- CONTEXTO HISTÓRICO.}

La conquista musulmana se inició con la batalla de Guadalete, en el año 711, donde los ejércitos de Tariq derrotaron a las tropas visigodas de Don Rodrigo. En poco más de ocho años, los musulmanes conquistaron la mayoría de la Península, ocupándola a lo largo de ocho siglos. La España conquistada recibió el nombre de AlAndalus y se convirtió en provincia del Imperio musulmán.

Durante la etapa del Emirato dependiente (711-755), Al-Ándalus se hallaba sometida al califa de Damasco, aunque sus emires dependían de Ifriqiya. En el año 756 llegó a la península Abd al-Rahmán, quien derrotó al emir Yusuf, representante del poder de Damasco, en la batalla de Alameda y se hizo proclamar emir con el nombre de Abd-al-Rahmán I, iniciándose la etapa del Emirato de Córdoba (756-929). En el año 773 se autoproclama emir independiente de los califas abassies, rompiendo sus relaciones con Damasco y fundando el Emirato de Córdoba.

A partir del reinado de Al-Hakam I comenzaron una serie de sublevaciones que durarán hasta la etapa siguiente, prolongándose durante los reinados de Abd al-Rahmán II, Muhammad I, Al-Mundir y Abd Allah. Esto supuso que muchos pensaran que el fin de la dominación musulmana estaba cerca, pero llegó al trono Abd al-Rahmán III y con él una nueva etapa.

Abd al-Rahmán III devolvió unidad y poder al reino, consiguiendo, incluso, importantes victorias frente a los cristianos del norte. Nos encontramos en la etapa del Califato de Córdoba (912-1031), la etapa de mayor esplendor de la España musulmana.

El más destacado del califato fue Abu Amir Muhammad, que recibió el título honorífico de “Almanzor”. A la muerte de Almanzor (1002) las luchas volvieron a apoderarse de Al-Andalus, perdiendo definitivamente su unidad.

El califato se mantuvo oficialmente hasta 1031 con Hisam III que fue el último califa nominal. A su muerte, Al-Andalus se dividió en treinta reinos, los reinos de taifas (1032-1232). Estos llamaron en su ayuda a otros pueblos musulmanes del norte de África: primero a los almorávides y luego a los almohades; sin embargo, irán desapareciendo a medida que la expansión cristiana progrese.

Tras la revuelta que se produjo en 1232 en Arjona, Muhammad I fue proclamado sultán. Éste entró en Granada en el año 1236 y la convirtió en capital del nuevo Reino Nazarí (1232-1492). A partir de aquí, el sultán se dedicará a conquistar territorios formando un reducido reino que va desde Gibraltar hasta Almería.

La vida del reino nazarí de Granada estuvo condicionada casi siempre por la presión del reino de Castilla y el temor a ser absorbido por el reino mariní de Marruecos. Sus últimos años estuvieron marcados por la prolongada guerra civil palatina (1419-1482). Boabdil, su último sultán, entregó Granada el 2 de enero de 1492 y los Reyes Católicos entraron en la ciudad el 6 de enero de ese mismo año.

Este es el fin de la España musulmana, dando paso a la etapa morisca. En ésta época, que transcurrió entre 1492 y 1570, se pueden diferenciar tres períodos con una coyuntura muy dispar ${ }^{1}$

\section{3.- LA ZAMBRA MORISCA.}

Antes de comenzar, es preciso recurrir a la etimología del término zambra. Según Cortés (1996), dicha palabra deriva de zamr que significa tañer o tocar (p. 471). No obstante han sido muchos los significados otorgados al

\footnotetext{
${ }^{1}$ Según Fernández, los tres períodos en los que se divide la época morisca, son los siguientes: entre 1492 y 1529 asistimos a un periodo de idílica convivencia musical; entre 1530 y 1565, cabría un segundo período en el cual comienzan a surgir los primeros problemas y prohibiciones; y, entre 1566 y 1560 acontecería un período tremendamente duro para los moriscos, en el cual serían suplantadas sus tradiciones populares y folklóricas. Ver FERNÁNDEZ, De las melodías del reino nazarí de Granada a las estructuras musicales cristianas. La transformación de las tradiciones musicales hispano-árabes en la península Ibérica. Granada: Diputación Provincial de Granada, 1985, pp. 5359 .
} 
vocablo a lo largo de la historia, entre los cuales encontramos "orquesta morisca", "baile de moro"', "fiesta morisca con música y algazar"' o "compañía de danzantes moro" (Moliner, 1988, p. 61).

La zambra constituía una de las manifestaciones más significativas de los musulmanes asentados en la península ibérica, por lo que continuó ejecutándose en tiempos de la Reconquista cristiana, época en que la población musulmana tuvo que convertirse a la religión imperante en la Monarquía hispánica, intentando, no obstante, mantener vivas sus tradiciones y costumbres.

Según Navarro (1995a), la popularidad de estos bailes fue considerable tanto en nuestro país como fuera del mismo (p. 174). En efecto, diversas escenas plasmadas en las artes plásticas atestiguan lo anteriormente dicho; tal es el caso de las figuras talladas en madera por Erasmus Grasser $^{2}$ en 1480 o los dibujos de Weiditz ${ }^{3}$ en el primer tercio del siglo XVI. Es interesante, siguiendo esta misma línea, el hallazgo de Roig (1995), quien encontró, en una lista de obras de Vélez de Guevara, el titulo "Baile de Moriscos", composición anónima que habría servido de intermedio en la representación de la comedia $\mathrm{La}$ Hermosura de Raquel (1615) del mismo autor (p. 591-592). En esta obra se pudieron apreciar las costumbres y maneras de manifestarse de aquellos que, un año antes al posible estreno de esta función (1614), habrían sido ordenados expulsar.

A partir de 1492, tal como apunta Manzano (1992), los musulmanes tuvieron que aceptar oficialmente la religión cristiana, pasando a pertenecer a la clase social morisca. En estos primeros años, se les permitió seguir practicando sus tradiciones, entre las cuales estaba la música y, por supuesto, la zambra. En efecto, el 13 de febrero de 1492, los Reyes Católicos otorgan "la carta de merced del oficio de alcalde de las juglaras y juglares de Granada a favor de Ayaya fisteli, conforme usaron tal cargo los alcaldes nombrados por los reyes moros", lo cual suponía la organización y oficialización de la música morisca (p. 133). Esta situación continuará años

\footnotetext{
${ }^{2}$ Se aprecian danzas al estilo morisco llevadas a cabo en Inglaterra, donde los bailarines usarían campanillas en las rodillas y pies, y se teñían el rostro de color oscuro para realzar el origen hispanomoro de los bailes. ${ }^{3}$ En estos aparecen una pareja de moriscos danzando acompañados de tres músicos.
}

más adelante, como se puede deducir de un requerimiento de 1517 hecho por los jurados del Ayuntamiento de Granada con el fin de que no se cobrase el derecho morisco "tarcón", en concepto de zambras, bodas y desposorios. Así, en 1519 este impuesto se extinguirá.

El ambiente de convivencia y tolerancia en estos primeros años estaba, pues, presente en la permisividad otorgada a las manifestaciones musicales, como era la música y la danza, mostrándose más intolerancia en lo referido a la religión. De hecho, ofrecían incluso muestras de sus bailes a aquellos que llegaban a cristianizarlos, ejecutándolos públicamente, tal como recogen algunas noticias sobre el caso de Granada en la festividad del Corpus Christi:

"El arzobispo santo (...) holgaba que acompañasen el Santísimo Sacramento en las procesiones del día de Corpus Christi, y de otras solemnidades, donde concurrían todos los pueblos a porfía unos de otros, cual mejor zamba sacaba, y en la Alpujarra, andando en la visita, cuando decía misa cantada, en lugar de órganos, que los había, respondían las zambras, y le acompañaban de su posada a la iglesia” (Mármol, 1797, p. 70).

Poco a poco la situación fue empeorando. A partir del segundo cuarto del siglo XVI, la idílica situación de convivencia comenzaba a invertirse, lo que conllevó repercusiones en el campo musical y, por ende, en la zambra. No obstante, dentro de las autoridades cristianas hubo quién constituyó una auténtica defensa de la música morisca; tal fue el caso de la reina Isabel de Portugal, que intercedería en varias ocasiones para que no desapareciese ese característico mundo sonoro de los moriscos.

En 7 de diciembre de 1526, tal como indica Navarro (1993), Carlos I promulgó una disposición para prohibir que se usasen zambras y leilas (p. 16-17). También prohibió el uso de alheña, así como las ceremonias moras en los casamientos. Además, en estas bodas habrían de oírse misas, y las puertas y ventanas de sus casas durante los festejos debían de estar abiertas. Por supuesto, se les prohibía que hablasen en árabe, el uso de sobrenombres moros, el vestir con ropas tradicionales, el acudir a los baños, cerrar las casas los viernes o sábados, y la posesión de niños expósitos o esclavos de origen berberiscos. Estas prohibiciones serían pasadas por alto en 
Granada a cambio de dinero, aunque no por mucho tiempo: el destierro estaba cada vez más cercano.

Las disposiciones estatales contra la religión y cultura morisca se repitieron asiduamente, consiguiendo así el pretendido debilitamiento de éstas. En 1566, según Fernández (1988), Diego de Espinosa junto a Felipe II prepararon un edicto que imponía varias prohibiciones a los moriscos (p. 147). Pedro de Deza, presidente de la audiencia de Granada, pondría en práctica el mismo en 1567. Ante éste, los moriscos protestarían durante un año, siendo muy interesante, en opinión de Luis de Mármol (1797), la intervención de Francisco Núñez Muley, quién recordaría la amplia historia de tolerancia existente en la península (pp. 69-71). Pese a ello, el edicto seguiría el camino delimitado por las autoridades cristianas, y en 1568 comenzaría en Granada la total expulsión de los moriscos, la cual tendría su fin en 1609.

No obstante, es lícito pensar, tal como señaló el arabista Ribera (2000), que son posibles las herencias musicales en las prácticas cristianas, al igual que otras muchas cosas nos han quedado de los mismos (p. 153-171). De esta forma, estas hipotéticas influencias también habrían podido impregnar elementos de la danza e incluso podrían persistir hoy día en nuestros bailes tradicionales.

\section{4.- LA ZAMBRA GITANA.}

El primer documento sobre la llegada de gitanos a nuestro país data de 1415 y está fechado en la ciudad de Perpignan, que en su día perteneció a la Corona de Aragón. En 1447 entran en Barcelona y en 1462, penetrando a través de Castilla, llegan a la ciudad de Jaén. Los gitanos se presentaron en Andalucía, al igual que en el resto de Europa, en grupos de 25 a 100 personas, siendo muy bien acogidos hasta principios del siglo XVI. A partir de esta fecha, se iniciará un cambio de actitud política que pretenderá, bien la integración de los gitanos o bien su expulsión, ya que se intentaba lograr un estado moderno basado en la unidad de residencia y la homogeneización del país. No obstante, esta comunidad se acogerá a la religión católica, con lo cual no serán expulsados.

Las pragmáticas reales que ordenaban el asentamiento de los gitanos se repetirán a lo largo del siglo XVI y XVII, no contribuyendo éstas a promover unas relaciones fluidas entre la comunidad gitana y la no gitana. Con el reinado de Carlos III se abre un nuevo período que llegará hasta nuestros días, caracterizado por la igualdad en los derechos y responsabilidades respecto al resto de la población (VV.AA., 1987, p. 13-23).

En efecto, como se expuso anteriormente, la llegada de los gitanos a la península, y en concreto a la ciudad de Granada, se producía de forma paralela al momento de la expulsión de los moriscos, comenzando así un período de convivencia entre los gitanos y aquellos moriscos, que huyendo de las autoridades cristianas, se refugiaban en estas comunidades marginales. Según Navarro (1995b), dicha convivencia se iniciaría en el barrio árabe de Rabadasif, y son varios los testimonios de cómo algunos moriscos se unían a las caravanas de los gitanos (p. 174). No obstante, la Inquisición descubriría la infiltración de la comunidad morisca entre la gitana.

Así pues, las huellas moriscas se habrían prolongado en el tiempo, y muchas de sus costumbres y tradiciones se transmitieron posiblemente a estas comunidades gitanas. Sin embargo, como indica Navarro (1993), la palabra zambra quedará enmudecida durante varios siglos, apareciendo de nuevo entre aquellos gitanos del Sacromonte granadino (p. 20). Estas zambras gitanas vendrían a ser la versión granadina de los cafés de cante que se constataban en tantas ciudades españolas durante la segunda mitad del siglo XIX.

Navarro (1995b) recoge la configuración que adoptaba la zambra decimonónica. Por lo general, cada una contaba con la presencia de un Capitán o Capitana que tenía el rol de director o coreógrafo y daba nombre al grupo. En dicha formación, también encontrábamos a uno o dos guitarristas y como mínimo a cuatro o seis bailaoras o bailaores. Normalmente estos miembros pertenecían a la misma familia del Capitán (p. 371-372).

El espectáculo de estas zambras variaba en función de lo que el espectador estaba dispuesto a pagar. De hecho, son muchas las noticias sobre el precio de una función.

Estas fiestas se convirtieron en una visita obligada para aquellos extranjeros que visitaban la ciudad de la Alhambra. No obstante, poco a poco fueron perdiendo espontaneidad, a la vez que se ganaba en automatización y en comercialidad.

Son muchas las zambras de las que nos han 
llegado noticias, entre las cuales podemos destacar la del El Cujón, La Golondrina, Juan Amaya o Pepe Amaya. Ya en el siglo XX, encontramos nuevas zambras como la de Lola Medina, Rosa la Faraona, Manolo Maya, Rocío, Pitirili o María la Canastera.

Singular es la descripción que hace Seco de Lucena (1929) sobre la zambra, recogida por Navarro (1995a):

"Un espectáculo verdaderamente sugestivo que, por su carácter oriental, fascina a los extranjeros son las danzas que los gitanos que viven en el Camino del Monte Sacro organizan en sus cuevas y que, según la feliz definición de Pérez Losa, constituyen un rito, porque las ejecutan las bailaoras en la exaltación de una fiebre que las va dominando, que las va poseyendo, que las hace vibrar con estremecimientos medulares, que ponen en sus ojos negros o en sus ojos verdes, la loca llamarada de las siete lujurias o la expresión torturada de los siete dolores...; son un rito, porque estas danzas tan expresivas, tan emotivas en los estremecimientos de su voluptuosidad y en los retorcimientos angustiosos de sus complicadas expresiones, tienen mucho de ceremonia, de sacrificio y de culto, siendo las más notables: El baile de la novia, representación coreográfica del casamiento de una gitana. Toman parte en ellas muchas mujeres, los músicos y el jefe que dirige la danza agitando unas sonajas. El tango gitano, por una bailaora. Los demás la jalean con gritos, piropos y palmas. El fandango, bailado por cuatro mujeres $y$ acompañado por el coro. La cachuca, pantomima coreográfica en la que se representa la solicitud de perdón que hace un gitano por haber robado a su novia. El baile de la azucena, por dos gitanillas acompañándose con castañuelas y jaleadas por el coro. El bolero gitano, que baila una mujer, a quien acompaña el coro con gritos y castañuelas. Los merengazos, por una mujer. Las sevillanas, bailadas por dos hombres y dos mujeres. La jota gitana, por cuatro mujeres y un hombre que se acompaña con un pandero. Además, merece citarse, como piezas de canto y música, las granadinas, coplas tristes que se cantan acompañándose con guitarra; y La sangre gitana, con acompañamiento de guitarras, bandurrias y castañuelas” (p. 375).

Pese a que, según diversos autores las inundaciones de 1962 y 1963 obligaron a desalojar gran parte del barrio granadino de El Sacromonte, la zambra granadina persiste en el sentir del folklore de la comunidad gitana dispersa en esta ciudad (VV.AA., 1987).

\section{5.- CONCLUSIONES.}

Como hemos podido observar a lo largo de esta exposición, las danzas tuvieron un protagonismo fundamental en el mundo andalusí. Los bailes estaban estrechamente ligados a la fiesta y a la reunión, lo cual tendría posiblemente orígenes beduinos y nexos con la comunidad gitana.

Las ceremonias domésticas, mucho más arraigadas entre la población andalusí, darían lugar a fiestas o zambras, realizadas para distintas celebraciones, donde la música y el baile estarían siempre presentes. Estas zambras serían objeto de numerosas proscripciones, que las conducirían a la intimidad así como a la clandestinidad, hasta que a partir de 1526 se prohibiese de forma definitiva.

De comprobarse que los moriscos expulsados se refugiaron entre las comunidades gitanas, con las cuales habrían compartido y transmitido conocimientos y prácticas musicales, se podría establecer un proceso de continuidad entre la música y la zambra morisca, y la música y la zambra gitana.

En efecto, tal como afirma Cruces (2003), son muchas las afinidades entre algunos bailes del mundo árabe, las danzas gitanas centroeuropeas y la plasticidad flamenca, gitana o no, para poder concurrir en un cierto origen común de todas ellas. Técnicas y prácticas como el braceo, el hieratismo, la introversión y la regla de oposición, nos situarían ante parentescos estéticos indiscutibles.

\section{6.- REFERENCIAS BIBLIOGRÁFICAS.}

Cortés, J. (1996). Diccionario de árabe culto moderno árabe-español. Madrid: Gredos.

Cruces, C. (2003). El flamenco y la música andalusí. Argumentos para un encuentro. Barcelona: Carena. 
Fernández, R. (1985). De las melodías del reino nazarí de Granada a las estructuras musicales cristianas. La transformación de las tradiciones musicales hispano-árabes en la península Ibérica. Granada: Diputación Provincial de Granada.

Fernández, R. (1988). La música de los moriscos del reino de Granada: La cara oculta del Renacimiento Español. Nasarre. Revista Aragonesa de Musicología, 4, 85-94.

Fernández, R. (1992). Las zambras de los moriscos del Reino de Granada. El Folk-lore Andaluz, 129-148.

Mármol, L. (1797). Historia del rebelión y castigo de los moriscos del reyno de Granada. Madrid: Imprenta de Sancha.

Moliner, M. (1988). Diccionario de uso del español (Vol. II). Madrid: Gredos.
Navarro, J. L. (1993). Cantes y Bailes de Granada. Málaga: Arguval.

Navarro, J. L. (1995a). Las zambras gitanas de Granada. En J. L. Navarro y M. Ropero (dir.) Historia del Flamenco (Vol. II, pp. 369377). Sevilla: Tartessos.

Navarro, J. L. (1995b). Los moriscos y sus zambras. En J. L. Navarro y M. Ropero (dir.) Historia del Flamenco, (Vol. I, pp. 173-182). Sevilla: Tartessos.

Ribera, J. (2000). La música árabe y su influencia en la española. Valencia: PreTextos.

Roig, A. (1995). Interpretation du baile de los moriscos (1615). Mélanges, 12, 591-609.

VV.AA. (1987). Antropología urbana de los Gitanos de Granada. Un estudio desde la Antropología aplicada al trabajo social. Granada: Ayuntamiento de Granada. 